\title{
Gestão de projetos e sua interface com o canteiro de obras sob a ótica da Preparação da Execução de Obras (PEO)
}

\author{
Design management and its interactions with construction \\ sites from the perspective of building pre-construction \\ management
}

\section{Aline Valverde Arrotéia \\ Tatiana Gondim do Amaral Silvio Burrattino Melhado}

Aline Valverde Arrotéia Universidade Federal de Goiás Goiânia - GO - Brasil

Tatiana Gondim do Amaral Universidade Federal de Goiás Goiânia - GO - Brasil

Silvio Burranttino Melhado Universidade de São Paulo Sao Paulo - SP - Brasil

Recebido em 12/02/14 Aceito em 04/09/14

\section{Resumo

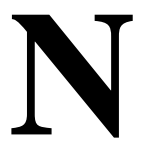

os últimos 20 anos, o setor da construção civil no Brasil evoluiu significativamente em resposta ao crescimento da competitividade no mercado. Entretanto, nesse processo de evolução ainda têm sido encontradas barreiras culturais e organizacionais, e, sobretudo, dificuldades nos esforços voltados à qualidade nos canteiros de obras. Aliada a este quadro, a falta de integração entre as atividades de projetar e construir provoca uma série de desperdícios, patologias, retrabalhos e alterações improvisadas decorrentes de projetos não compatibilizados, ora por ausência de detalhes nos projetos, ora por decisões tomadas por pessoas não capacitadas em momentos inadequados. O presente trabalho tem como objetivo geral discutir a implementação do método da preparação da execução de obras (PEO) a fim de melhorar a qualidade na interface projeto-execução de obras. O método de pesquisa adotado para o desenvolvimento deste trabalho é classificado como qualitativo e foi realizada por meio de pesquisa-ação. Os resultados obtidos com a realização da pesquisa comprovaram a eficácia do método da PEO e a sua viabilidade na melhoria da gestão da interface projeto-execução de obras, em empresas de incorporação e construção de edifícios.

Palavras-chaves: Preparação da Execução de Obras. Coordenação pró-ativa. Canteiro de Obras. Gestão de Projetos. Comunicação.

\section{Abstract}

During the past twenty years, the construction industry in Brazil has evolved significantly in response to the market's growing competitiveness. However, in this evolution, there have been several cultural and organizational barriers, and difficulties in the effort to improve quality in construction sites. Besides, the lack of integration between design andconstruction processesresults in waste, pathologies, rework and improvised changes originated fromclashes indesign, either due to lack of design detailing or to decisions being taken by unskilled staff at inappropriate moments. The aim of this study is to discuss the implementation of the Building Pre-Construction Management (PCM) method, in order to improve the management of the design process in its interface with the construction site. The research method adoptedin this study can be classified as qualitative and it was conducted through action-research. The results indicated that the effectiveness and feasibility of using PCM to improve the management of the design-construction interface, in real estate and building companies.

Keywords: Building pre-construction. Management. Pro- active coordination. Construction site. Design management. Communication. 


\section{Introdução}

A produção arquitetônica contemporânea vivencia uma cultura de consumo diante dos desafios atuais, tais como o mercado internacional, a aceleração contínua da industrialização, o aumento da complexidade envolvida na construção e o uso da tecnologia da informação e comunicação. Essa nova realidade exige maiorclareza, padronização e controle no processo construtivo, a fim de obter melhor qualidade na arquitetura do produto final (BEIM; JENSEN, 2007).

Acerca dos últimos 20 anos, Manso e Mitidieri Filho (2011) afirmam que a realidade da construção civil modificou-se significativamente em virtude da prática dos sistemas de gestão da qualidade, o que resultou em um avanço para o setor. Assim como em outros países, no Brasil são identificadas necessidades de reformulação nos aspectos relacionados às pessoas, processos, tecnologia e dados envolvidos no processo de projeto, a fim de atender às necessidades de crescimento e melhorar a qualidade da construção civil (MANZIONE, 2013).

Yang e Wei (2010) apontam que a falta de planejamento, a fragmentação das etapas de projeto e execução de obras influenciam diretamente no custo final do empreendimento, o que gerabaixa produtividade e qualidade do produto final. Kovacic, Oberwinter e Müler (2013) afirmam que a alta fragmentação das etapas relacionadas à concepção e àconstrução de edifícios interfere na gestão das atividades que envolvem o planejamento e a execução de um empreendimento.

Dessa forma, partindo da ideia de usar o planejamento a fim de evitar perdas e retrabalhos, somada ao apoio do movimento da qualidade ${ }^{1}$, as organizações francesas desenvolveram métodos de gestão - PEO e Coordenação Proativa (CPA) -, com o intuito de alcançar maior integração entre os agentes responsáveis pelo projeto e execução da obra; maior conhecimento do projeto por parte da equipe de execução; maior comunicação, participação e colaboração entre os agentes (SOUZA; MELHADO, 2003).

A PEO é considerada um conjunto de reuniões sistematizadas que se destinam à análise crítica dos projetos, ao planejamento das atividades e àpreparação do canteiro de obras. Pesquisas publicadas no Simpósio Brasileiro de Qualidade

${ }^{1} \mathrm{Na}$ França, as primeiras propostas para desenvolver modelos de gestão da qualidade específicos para a construção surgiram entre 1990 e 1992, período no qual houve intenso envolvimento dos profissionais e das instituições no desenvolvimento de estudos, pesquisas, orientações e normas voltados para a qualidade na construção (MELHADO, 2001). do Projeto - SBQP 2013 apontaram a importância da interação e comunicação entre os agentes envolvidos, por meio da sistemática de reuniões periódicas, formando um time de construção, como uma das estratégias na integração da interface projeto-execução de obras. Autores como Tosta e Calmon (2013) e Sanchez e Andery (2013) discutem os resultados obtidos com essas pesquisas.

O presente artigo é resultado de uma dissertação de mestrado que teve como objetivo implementar o método da PEO para avaliar a interface entre a gestão do processo de projeto e a execução do canteiro de obras.Como contribuição para o avanço do conhecimento buscou-se avaliara aplicação do método da PEO em um cenário diferente da realidade encontrada nos canteiros de obras franceses, assim como na construção de edifícios na cidade de São Paulo desenvolvida por Souza (2001).

\section{Gestão da interface projeto- execução de obras}

A indústria da construção sofre com a fragmentação ao longo das fases do ciclo de vida do empreendimento. Os projetos são desenvolvidos por um grande número de agentes, tais como o empreendedor, os projetistas, os consultores, os subcontratados e os fornecedores. Todos deveriam trabalhar em conjunto, tanto na fase de projeto, como na fase de execução, em razão da complexidade de se construir um edifício (XUE; SHEN; REN, 2010).

Na óptica de Mitchell et al. (2011), a indústria da construção se comporta de forma fragmentada devido à organização de etapas isoladas, nas quais os processos de projeto e execução são desenvolvidos separadamente por diferentes agentes, com suas responsabilidades, objetivos e metas em prazos diferentes.

Durante as etapas iniciais de desenvolvimento do projeto, a interação entre os diferentes agentes ocorre livremente, uma vez que a carga de informações ainda é pequena. Com o passar do tempo, a quantidade de informações produzidas aumenta, assim como o surgimento de novos agentes formais e informais, o que configura a necessidade de comprometimento dos profissionais envolvidos anteas fases de projeto e execução (EMMITT, 2010).

A interação das equipes de projeto ou de construção está diretamente relacionada às práticas de comunicação empregadas, asua organização e

184 Arrotéia, A. V.; Amaral, T. G. do; Melhado, S. B. 
àforma como foi estruturada (HILL, 1995; AZAM et al., 1998; THOMAS et al., 1998). Sendo assim, para agenciar a equipe de projeto, deve-se estabelecer um coordenador de projetos responsável pelo planejamento das atividades e pela definição das reuniões destinadas àintegração das equipes, dos escopos do projeto e dos cronogramas de trabalho (MARTINS; ANDERY; STARLING, 2013).

Dessa forma, o coordenador de projetos deve fomentar a cooperação, a comunicação e o compromisso em um ambiente de projeto dinâmico,que envolva toda a equipe. Por isso, ele deve possuir um alto grau de liderança para lidar com as interações entre os agentes envolvidos durante o processo de projeto de um empreendimento (EMMITT; PRINS; OTTER, 2009).

Segundo Andi (2003), os projetistas reconhecem que a falta de conhecimento do processo construtivo resulta em soluções projetuais equivocadas, e muitas vezes impraticáveis, o que contribui para um produto construído de baixa qualidade. Para o autor, os profissionais de projeto devem envolver-se de modo mais efetivo durante a fase de produção do edifício, pois hoje o papel do projetista é praticamente inexistente no que tange à gestão e à execução da obra de um edifício.

Para tanto, faz-se necessário que todos os agentes envolvidos na construção de um edifício, sejam eles arquitetos, engenheiros, empreendedores, subempreiteiros e consultores, assumam novos papéis dianteda gestão e da elaboração do projeto, assim como na execução do empreendimento, formando uma equipe de construção (EDWIN et al., 2005).

A equipe de construção deve ser compostade uma série de indivíduos ou grupos que busquem alcançar metas individuais, e ao mesmo tempo coletivas, organizadas em uma sistemática a qual se denomina de "equipe de projeto". Por isso, deve ser entendida como um grupo independente, composto de agentes interessados na execução de um projeto específico, de tal modo que seja formada por vários especialistas de áreas diferentes, na qual cada um contribua com seu conhecimento profissional específico, intenções e expectativas em relação aos outros membros da equipe (EMMITT; GORSE, 2007).

Portanto, a integração da interface projeto-obra e dos agentes envolvidos requer planejamento, organização, disciplina e aceitação do processo por parte de todos os membros da equipe, pois a definição clara da gestão do projeto com as funções e prazos estabelecidos antes do início das atividades reflete positivamente no envolvimento da equipe, tornando-a mais integrada e motivada diante de novo desafio (VENTURA; PRATSCHKE, 2013).

Além disso, Prieto, Páez e Vargas (2011) descrevem que a seleção do software ou das ferramentas computacionais que apoiam a elaboração de projeto deve estar associada às exigências $\mathrm{e}$ às necessidades para $\mathrm{o}$ desenvolvimento integrado do modelo e que, para facilitar a prática gerencial, organizacional e a documentação dos processos da empresa, a escolha da ferramenta deve considerar certos aspectos, entre os quais: facilidade de uso da ferramenta; flexibilidade para melhoria contínua dos processos; gestão dos documentos; e alocação de recursos.

Com isso, pode-se afirmar que o uso de ferramentas computacionais e de softwares apropriados torna-se uma eficiente ferramenta de gestão para a interface projeto-execução de obras. Todavia, deve-se avaliar a melhor forma de implementá-los, para que se obtenha maior produtividade (PIERCE JUNIOR, 2004).

Em suma, o aumento da complexidade dos projetos e dos processos envolvidos na construção de empreendimentos acarretou a necessidade de inserção de uma mentalidade industrial por meio da aplicação do modelo tridimensional para a concepção do produto. Assim, a partir dessa noção atual de concepção e projeto, originou-se o conceito Building Information Modeling(BIM), caracterizado como uma modelagem que prioriza a integração de todos os processos relacionados à construção do produto edificação (SOUZA; AMORIM; LYRIO, 2009).

\section{Preparação da Execução de Obras (PEO)}

A PEO é considerada uma fase de transição entre o desenvolvimento do projeto e a execução da obra, com o objetivo de aprimorar o projeto, planejar a execução da obra, rever os projetos entregues e envolver as equipes de projeto e execução. Reserva também uma fase para os ajustes necessários do projeto no canteiro de obras por meio de reuniões sistematizadas (MELHADO et al., 2006).

A PEO deve ser entendida como um período de antecipação coletiva, de coordenação e de identificação das deficiências potenciais de uma obra. De acordo com Melhado (2001), é neste período que é possível antecipar as decisões a partir do estudo das soluções do projeto, evitando conflitos entre as fases de projeto e da obra que comprometem a qualidade e o desempenho final do empreendimento. 
Segundo Romano (2003), a preparação da execução de obras é classificada como a terceira fase do processo de desenvolvimento de uma edificação, após a realização do planejamento e da elaboração do projeto. Por isso, é considerada uma fase de articulação racional entre os projetos, o planejamento e a execução da obra. Na Figura 1 está ilustrada a inserção da preparação da execução de obras no processo de projeto durante o desenvolvimento de um empreendimento/edificação.

Souza e Melhado (2003) destacam os dez principais objetivos que a PEO objetiva atingir:

(a) validação ou elaboração de estudos que complementem a viabilidade técnica e econômica das decisões de projeto;

(b) estabelecimento das soluções para os detalhes de projeto e sua validação;

(c) revisão dos memoriais descritivos separado por projeto ou por subsistema;

(d) solicitação das amostras e protótipos dos produtos e sistemas a serem utilizados na execução de obras;

(e) estudo e solução dos problemas das interfaces ante os variados serviços;

(f) estabelecimento e validação dos pontos de controle;

(g) análise e verificação no local dos fatores intervenientes externos;

(h) elaboração de projeto do canteiro de obras que defina, por exemplo, o local de estocagem dos materiais, os acessos, as instalações provisórias e o transporte vertical, visando a um local de trabalho mais organizado; (i) detalhamento do cronograma físico para a execução dos serviços; e

(j) documentação que relate o desenvolvimento dos trabalhos durante a PEO, por meio de atas de reunião.

Desse modo, na primeira reunião devem-se estabelecer as atividades que serão desenvolvidas ao longo da fase de preparação da execução de obras por meio de um cronograma com as datas das reuniões subsequentes. A frequência das reuniões deve estar associada ao porte do empreendimento e a seu cronograma de atividades. Souza (2001) sugere encontros semanais ou quinzenais com duração máxima de três horas por reunião, para que sejam produtivas.

Por isso, indispensável que a pauta com o conteúdo da reunião seja antecipada, para que haja uma sequência na discussão dos problemas a partir dos pontos anteriormente listados. Logo, durante as reuniões de PEO, devem ser verificados (SOUZA; MELHADO, 2003):

(a) a definição e a realização dos detalhes de projeto que orientam a execução dos serviços;

(b) a coerência entre os projetos para produção e os projetos de arquitetura, estruturas e instalações, entre outros;

(c) a apresentação de catálogos e documentos que contenham a certificação técnica dos produtos;

(d) a previsão do fornecimento de materiais e formas de estocagem; e

(e) o planejamento das atividades, em especial para as interfaces.

\section{Figura 1 - 0 processo de projeto no contexto do desenvolvimento de um empreendimento/edificação}

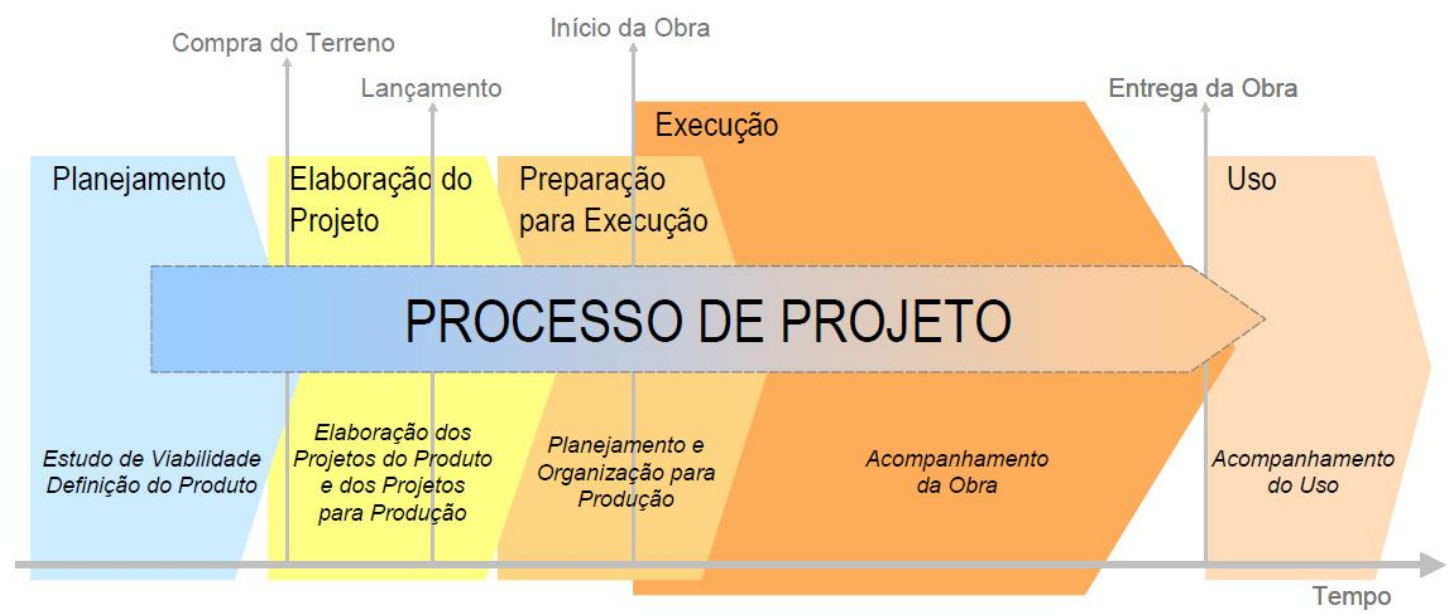

Fonte: Romano (2003). 
Todas as reuniões devem ser formalizadas por meio de atas, as quais devem ser transmitidas a todos os envolvidos na construção do empreendimento. O intuito é registrar as informações e as decisões efetuadas, de modo que a cada nova reunião sejam revisados os pontos destacados na reunião anterior (SOUZA; MELHADO, 2003).

$\mathrm{Na}$ Figura 2 está ilustrado o modelo de planejamento geral das reuniões coletivas de PEO, o qual deve ser acordado com todos os agentes envolvidos na construção a partir de uma sistemática de reuniões que promovam o planejamento, a organização, o controle e o gerenciamento dos projetos e do canteiro (RÉGIE..., 2011).

O National Institute of Standards and Technology e o Construction Industry Institute afirmam a importância de se planejar e organizar o processo de produção, uma vez que as decisões tomadas durante o planejamento nas diversas fases do projeto e da construção influenciam de forma direta a eficiência e eficácia da construção (CONSTRUCTION..., 2012).

De acordo com Austin et al. (1999), nos últimos anos houve aumento na compreensão da importância do uso de métodos que promovam o desenvolvimento do processo de projeto integrado com o orçamento e os métodos utilizados durante a execução de obras, a fim de minimizar os efeitos das variações ocorridas durante o processo de construção do edifício.

Além disso, estudo recente reportou que decisões antecipadas, somadas a um planejamento confiável, impactam de modo considerável na segurança e nas instalações críticas durante todo o ciclo de vida da construção (SAID; EL-RAYES, 2010).

Dessa forma, para a organização das reuniões e o agenciamento desses agentes, é fundamental que exista a figura do gestor do projeto para que os ajustes e as melhorias promovidas na gestão do processo de projeto maximizem a produtividade $\mathrm{e}$ a qualidade das atividades no canteiro de obras (ECOLE..., 2004).

Figura 2 - Planejamento geral das reuniões coletivas de PEO

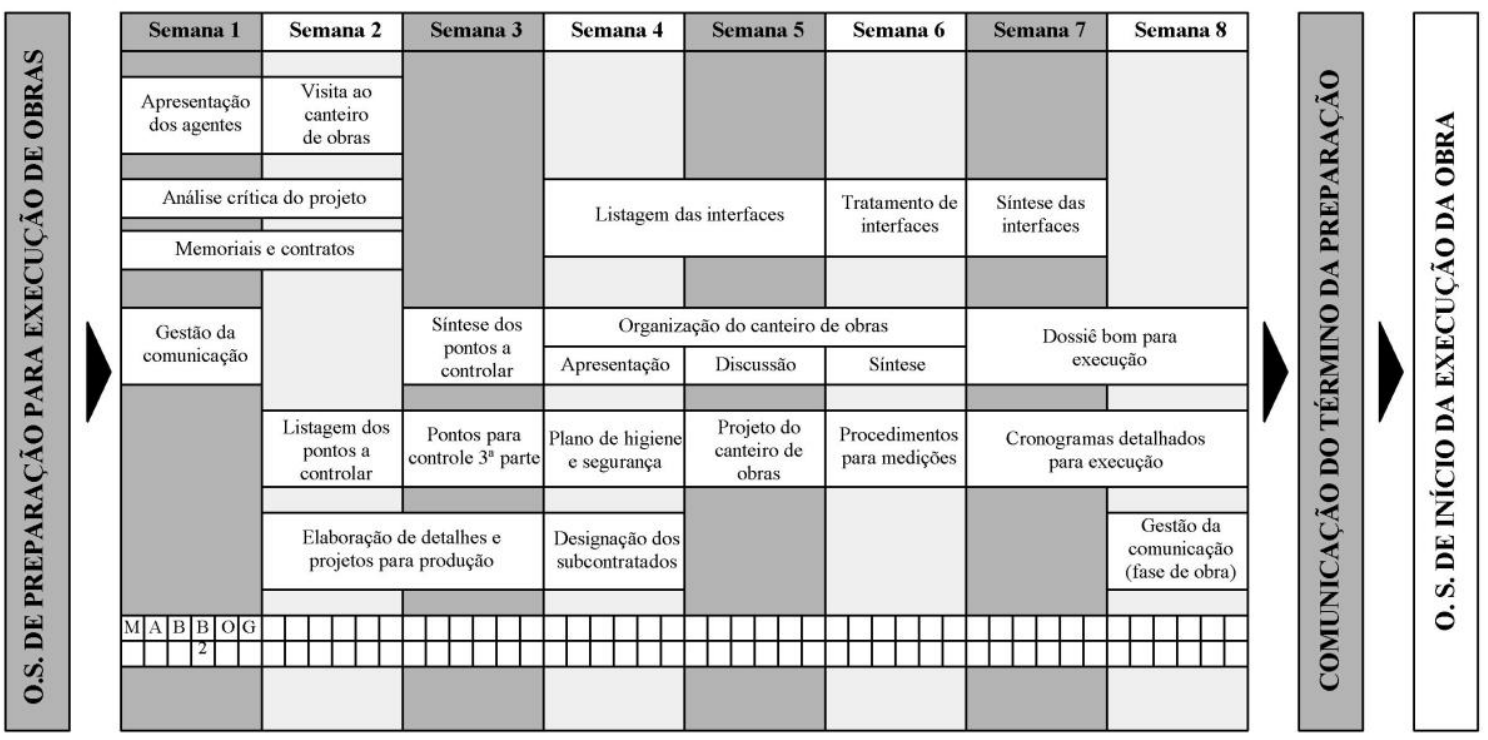

\begin{tabular}{|c|c|c|c|}
\hline & AGENTES PARTICIPANTES DA & UNIÕES & \\
\hline $\begin{array}{l}\text { M: Maitre d'Ouvrage (empreendedor) } \\
\text { A: Maitre d'OEuvre (arquiteto) } \\
\text { B: Projetista de engenharia }\end{array}$ & $\begin{array}{l}\text { B2: Controlador técnico } \\
\text { O: Coordenador da execução de obras } \\
\text { G: Topógrafo }\end{array}$ & $\begin{array}{l}\text { G2: Geólogo } \\
\text { E: Empresa construtora } \\
\text { S: Subcontratados }\end{array}$ & $\begin{array}{l}\text { C: Concessionárias } \\
\text { H: Higiene e segurança }\end{array}$ \\
\hline
\end{tabular}

Fonte: adaptado de Souza e Melhado (2003). 


\section{Método de pesquisa}

O método de pesquisa adotado para o desenvolvimento deste trabalho é classificado como qualitativo e foi realizado por meio de estudos de caso,em virtude dascaracterísticas do método da PEO. São elas:

(a) ser um trabalho coletivo, que envolva os agentes responsáveis pelo projeto e pela execução, reduzindo os problemas de integração entre as fases de projeto e execução da obra;

(b) ser um trabalho que antecipe as decisões, evitando que elas sejam tomadas no canteiro de obras diante da necessidade de um cronograma, sem considerar aspectos como custo, racionalização e desempenho; e

(c) ser um trabalho desenvolvido dentro de um tempo compatível com o atendimento dos objetivos, compreendendo como uma fase de interligação entre o projeto e a obra, no momento em que é possível estudar e planejar sua execução.

Diante do interesse em reduzir os problemas ocasionados pela falta de integração entre as fases de projeto e obra, o processo de pesquisa foi consolidado a partir da intervenção da pesquisadora em conjunto com os agentes envolvidos na interface projeto-execução de obras em dois empreendimentos localizados na região metropolitana de Goiânia, GO.

Ométodo adotado viabilizou a criação de um ambiente de trabalho coletivo e participativo entre todos os agentes envolvidos no processo, no qual foi possível observar, refletir e explorar a dinâmica de colaboração de forma contínua por um tempo estimado de 2 meses para cada um dos empreendimentos estudados.

\section{Etapas de pesquisa}

A pesquisa dividiu-se em duas etapas, definidas da seguinte maneira:

(a) estudo piloto da PEO na empresa A: estudo do método com o intuito de conhecer as atividades, as ações e os agentes responsáveis durante a fase de PEO para que, após sua aplicação, fosse possível analisá-lo criticamente para a implementação da PEO na empresa B; e

(b) implementação da PEO na empresa B: realizada após a aplicação do estudo piloto na empresa A, a fim de avaliar osresultados da aplicação do método em empresas com aspectos organizacionais e departamentais diferentes.

Como o resultado potencial da PEO está diretamente ligado a sua organização, e em virtude do porte e da complexidade dos empreendimentos estudados nas empresas A e B, a preparação da execução de obras foi subdividida em dois momentos:

(a) $1^{\circ}$ momento: envolveu a preparação técnica dos serviços relacionados com a obra bruta, realizada antes do início dos serviços de execução da estrutura, em paralelo ao movimento de terra e aos serviços de fundação; e

(b) $2^{\circ}$ momento: consistiu na revisão dos serviços de obra fina, realizada durante a execução da obra bruta.

Tanto para o estudo piloto como para a implementação da PEO foram incluídas somente as atividades relacionadas aos serviços de obra bruta, uma vez que não houve tempo hábil para a preparação técnica dos serviços de obra fina nos dois empreendimentos estudados, em virtude do prazo estabelecido para a realização da pesquisa.

Nas duas etapas discutiu-se sobre os projetos de arquitetura, estruturas, fundações, formas, vedações, impermeabilização, ar condicionado, prevenção e combate aincêndio, instalações elétricas e hidrossanitárias, assim como o leiaute e o plano de segurança do canteiro de obras. O delineamento da pesquisa adotado no trabalho está ilustrado na Figura 3.

\section{Critérios de seleção das empresas}

Os seguintes critérios foram considerados na seleção das empresas para a aplicação do método da PEO:

(a) ser uma empresa de incorporação e construção certificada ou em processo de certificação voltado à gestão da qualidade;

(b) ter como nicho de mercado a região metropolitana de Goiânia, GO, e ser representativa no ramo de incorporação e construção nesse cenário;

(c) desenvolver empreendimentos residenciais ou comerciais;

(d) ter interesse na realização da pesquisa; e

(e) apresentar porte, especialidade e estruturas organizacionais e departamentais diferentes, com o intuito de analisar a influência desses aspectos no resultado final, com a aplicação do método.

\section{Planejamento e organização das reuniões}

As reuniões foramrealizadas antes do início dos serviços no canteiro de obras dos empreendimentos eprogramadas periodicamente, semanal ou quinzenalmente. $\mathrm{Na}$ primeira reunião 
foi apresentado um cronograma com o planejamento das atividades a serem cumpridas durante todo o período de desenvolvimento da PEO, com as datas referentes às reuniões subsequentes. No Quadrolestá exemplificado o cronograma das reuniões entregue para os agentes que formaram a equipe multidisciplinar.

Com a intenção de esclarecer os papéis e definir as responsabilidades de cada agente, elaborou-se um quadrocom as reuniões eos responsáveis pelo desenvolvimento delas na fase intensiva da PEO (Quadro 2).

Naconformação inicial proposta para a equipe multidisciplinar, foi definida a participação dos seguintes agentes: o empreendedor, os projetistas, os consultores, os subempreiteiros, o técnico de segurança, o coordenador de projeto, o coordenador de obras ou coordenador proativo, o coordenador de PEO e o engenheiro residente. Todavia, a equipe foi formada a partir dos profissionais das duas empresas no momento da pesquisa.

Os agentes que formaram a equipe multidisciplinar durante a fase de PEO foram convidados a participar das reuniões de acordo com a temática a ser discutida, associada à área de conhecimento de cada um dos profissionais envolvidos. Destaca-se que não foi necessária a participação de todos agentes em todas as reuniões para a aplicação da PEO.

Figura 3 - Delineamento da pesquisa

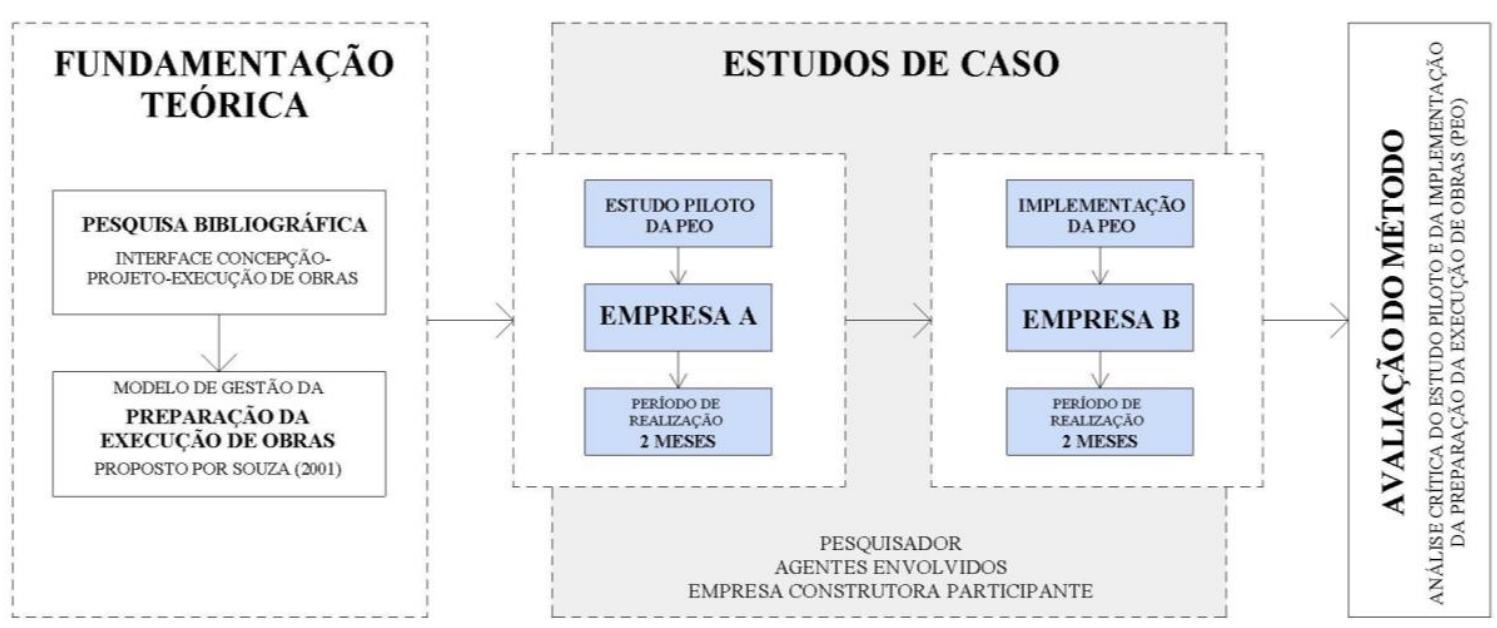

Quadro1 - Modelo padrão do cronograma das reuniões de PEO

\begin{tabular}{|c|c|c|c|c|c|c|c|c|}
\hline \multicolumn{9}{|c|}{ MODELO PADRÃO CRONOGRAMA DAS REUNIÕES DE PEO } \\
\hline \multicolumn{9}{|c|}{ ESTUDO PILOTO NA EMPRESA A / IMPLEMENTAÇÃO NA EMPRESA B } \\
\hline MÊS/ANO & \multicolumn{4}{|c|}{ MÊS/ANO } & \multicolumn{4}{|c|}{ MÊS/ANO } \\
\hline DIA/MÊS & $\begin{array}{c}\text { Data/Mês } \\
\text { Dia da semana }\end{array}$ & \begin{tabular}{|c|} 
Data/Mês \\
Dia da semana
\end{tabular} & \begin{tabular}{|c|} 
Data/Mês \\
Dia da semana
\end{tabular} & $\begin{array}{c}\text { Data/Mês } \\
\text { Dia da semana }\end{array}$ & $\begin{array}{c}\text { Data/Mês } \\
\text { Dia da semana }\end{array}$ & \begin{tabular}{|c|} 
Data/Mês \\
Dia da semana
\end{tabular} & \begin{tabular}{|c|} 
Data/Mês \\
Dia da semana
\end{tabular} & \begin{tabular}{|c|} 
Data/Mês \\
Dia da semana
\end{tabular} \\
\hline $\begin{array}{l}\text { Lançamento } \\
\text { da PEO }\end{array}$ & $1^{a}$ REUNIÃO & & & & & & & \\
\hline $\begin{array}{c}\text { Desenvolvimento } \\
\text { da PEO }\end{array}$ & & $2^{a}$ REUNIÃO & $3^{a}$ REUNIÃO & $4^{a}$ REUNIÃO & $5^{a}$ REUNIÃO & $6^{a}$ REUNIÃO & $7^{\mathrm{a}}$ REUNIÃO & \\
\hline $\begin{array}{l}\text { Finalizacão da fase } \\
\text { intensiva } \\
\text { da PEO }\end{array}$ & & & & & & & & $8^{a}$ REUNIÃO \\
\hline
\end{tabular}


Quadro 2 - Definição dos agentes responsáveis em cada reunião de PEO

\begin{tabular}{|c|c|c|}
\hline \multicolumn{3}{|c|}{ AGENTES RESPONSÁVEIS PELA ORGANIZAÇÃO DAS REUNIÕES DE PEO } \\
\hline FASES DA PEO & $\begin{array}{l}\text { REUNIÃO/ } \\
\text { SEMANA }\end{array}$ & AGENTE RESPONSÁVEL \\
\hline $\begin{array}{l}\text { Lançamento } \\
\text { da PEO }\end{array}$ & $1^{\mathrm{a}} \mathrm{REUNIÃO}$ & coordenador de PEO e coodenador pró-ativo \\
\hline \multirow{6}{*}{$\begin{array}{l}\text { Desenvolvimento } \\
\text { da PEO }\end{array}$} & $2^{\mathrm{a}} \mathrm{REUNIÃO}$ & $\begin{array}{l}\text { coordenador de PEO, coodenador pró-ativo, engenheiro residente } \\
\text { e técnico de segurança }\end{array}$ \\
\hline & $3^{\mathrm{a}} \mathrm{REUNIÃO}$ & coordenador de PEO e coodenador pró-ativo \\
\hline & $4^{\mathrm{a}} \mathrm{REUNIÃO}$ & coordenador pró-ativo e engenheiro residente \\
\hline & $5^{\mathrm{a}} \mathrm{REUNIÃO}$ & $\begin{array}{l}\text { coordenador de PEO, coodenador pró-ativo, engenheiro residente } \\
\text { e técnico de segurança }\end{array}$ \\
\hline & $6^{\mathrm{a}} \mathrm{REUNIÃO}$ & coordenador de $\mathrm{PEO}$, coodenador pró-ativo e engenheiro residente \\
\hline & $7^{\mathrm{a}}$ REUNIÃO & coordenador de PEO e coodenador pró-ativo \\
\hline $\begin{array}{l}\text { Finalização da fase } \\
\text { intensiva da PEO }\end{array}$ & $8^{\mathrm{a}} \mathrm{REUNIÃO}$ & coordenador de PEO e coodenador pró-ativo \\
\hline
\end{tabular}

Durante o período das reuniões, foi indispensável apreparação de uma pauta com a sequência dos pontos a serem tratados. Assim, à medida que os problemas eram resolvidos, os agentes eram liberados, e os demais eram incorporados à reunião. Dessa maneira, as reuniões visaram atender essencialmente ao:

(a) controle e planejamento das atividades;

(b) controle da conformidade técnica de execução;

(c) cumprimento do previsto com o que realmente foi realizado; e

(d) favorecimento da comunicação entre os agentes.

\section{Métodos e técnicas de coleta de dados}

Os instrumentos utilizados para a coleta de dados foram:

(a) análise de documentos das empresas A e B;

(b) utilização de software de gestão ou intranet para levantamento de dados, tais como projetos, memoriais, procedimentos de execução e controle ou instruções de serviços, indicadores, entre outros;

(c) cadernos de projetos de detalhamento e manuais; (d) fichas de solução das interfaces entre serviços;

(e) lista-mestra de projetos e de controle de documentos;

(f) entrevistas com os agentes participantes;

(g) observações participantes por meio das reuniões, visitas aos canteiros de obras e treinamentos, quando necessário;

(h) análise da documentação gerada ao longo da fase da preparação da execução de obras;

(i) questionário de avaliação do método sob a óptica dos agentes participantes; e

(j) atas de reunião.

A avaliação do método objetivou avaliar a implementação da fase de PEO, por meio de uma análise qualitativa sob duas ópticas distintas. Em primeiro lugar, a avaliação foi realizada a partir da opinião dos agentes envolvidos na aplicação do método e, em um segundo momento, a partir da discussão dos resultados obtidos durante a pesquisa.

Dessa forma, para a avaliação do método sob a óptica dosagentes, foi realizada entrevista estruturada por meio de um questionário, o qual deveria ser aplicado aos três agentes representantes da empresa que participaram de modo mais ativo nas atividades desenvolvidas durante a fase de PEO: o coordenador proativo; o engenheiro residente; e o coordenador de projetos. 
A escolha dos agentes foi definida a partir da ideia de se coletarem opiniões diferentes sobre a implementação do método da preparação da execução de obras, uma vez que cada profissional possui uma área de conhecimento específico e ocupa uma função distinta na estrutura organizacional da empresa.No apêndice deste artigo apresenta-se o questionáriodesenvolvido a partir dos cinco pontos principais, que nortearam a elaboração dedoze perguntas aplicadas:

(a) as ações desenvolvidas na fase de PEO;

(b) odesenvolvimento das reuniões e a participação dos agentes;

(c) a estrutura organizacional e departamental das empresas;

(d) a gestão e a coordenação de projetos; e

(e) o formato de contratação dos projetistas e subempreiteiros.

\section{Análise de dados e discussão de resultados}

\section{Caracterização da empresa A: estudo piloto}

A empresa A é uma empresa incorporadora e construtora de médio porte, com 16 anos de atuação, principalmenteno Estado de Goiás. Tem como especialidade incorporar e construir edifícios residenciais multifamiliares de baixo e médio padrão, e habitações de interesse social pelo programa Minha Casa, Minha Vida, do Governo Federal.
A empresa iniciou em 2012 a implementação do Software Integrado de Gestão (Sienge) e a implementação da ISO 9001 e PBQP-H.A administração é formada por uma equipe de 40 funcionários: engenheiros residentes, mestres de obras, encarregados, administrativos de obras, técnicos de segurança, almoxarifes e estagiários. $\mathrm{Na}$ produção, a equipe é composta de 189 funcionários próprios e 71 terceirizados.

\section{Caracterização do empreendimento 1: estudo piloto da PEO}

Para a aplicação do estudo piloto da PEO, escolheu-se um empreendimento residencial localizado na região metropolitana de Goiânia, GO. Projetado com três torres de apartamentos residenciais, possui mais de $5.000 \mathrm{~m}^{2}$ de área de lazer (pavimento térreo) e encontra-se em construção em um terreno com $11.650 \mathrm{~m}^{2}$.

O empreendimento envolveu a construção de duas torres de 18 pavimentos cada e uma torre com 19 pavimentos, com previsão de entrega para dezembro de 2014. Na Figura 4 está ilustrado o empreendimento 1, escolhido para desenvolvimento do estudo piloto da pesquisa.

Cada torre possui seis apartamentos por andar, sendo quatro apartamentos de três quartos e dois apartamentos de dois quartos. As vagas de garagens estão localizadas no pavimento térreo e no subsolo 1, e somam um total de 553 unidades, das quais 299 são vagas simples e 254 são vagas duplas.

Figura 4 -Fachada frontal do empreendimento 1

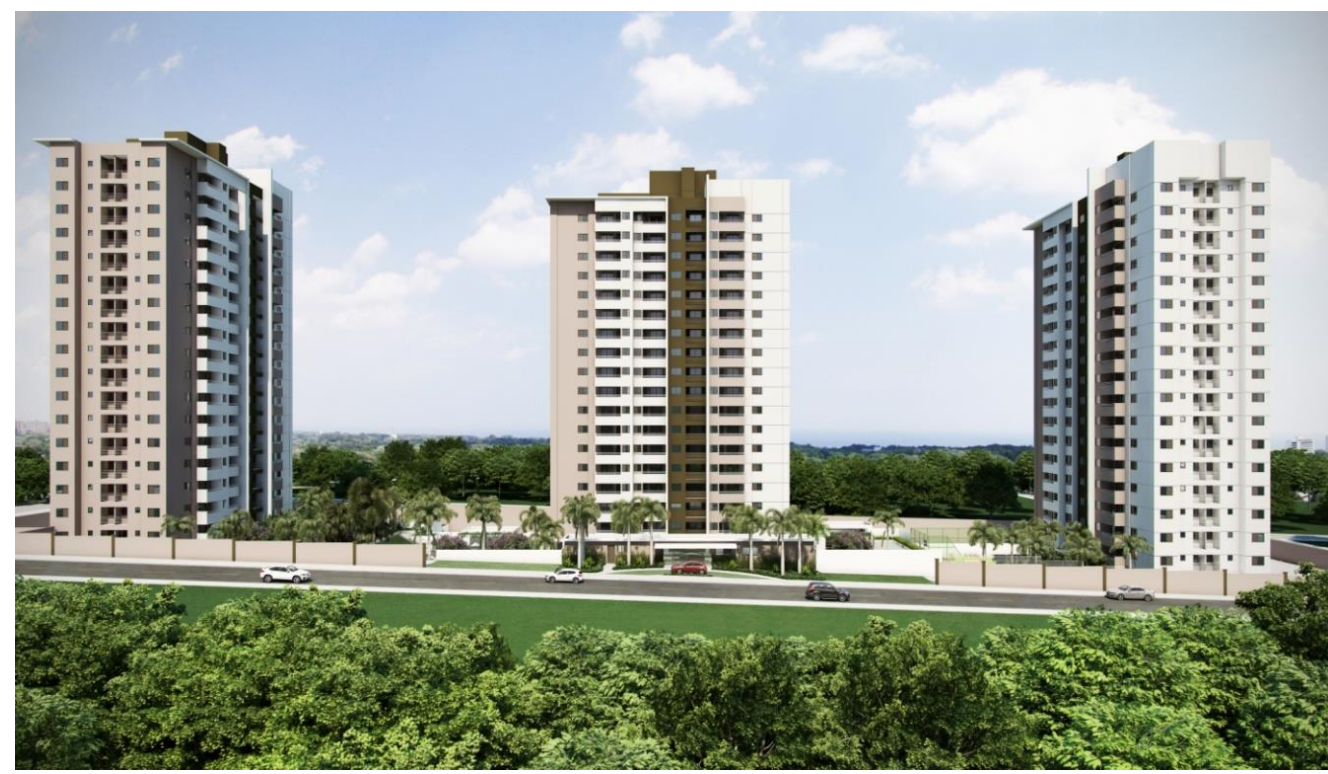




\section{Caracterização da empresa B: implementação da PEO}

Fundada em 1999, a empresa B é de médio porte no ramo de incorporação e construção, tendo como especialidade incorporar e construir edifícios residenciais multifamiliares, edifícios comerciais e hotéis de médio e alto padrão na cidade de Goiânia.

A empresa é certificada na ISO 9001 e PBQP-H Nível A desde 2005. O corpo administrativo inclui 52 funcionários na sede, enquanto a equipe de produção conta com 225 funcionários próprios e 400 operários terceirizados.

A empresa adota os programas UAU! e o MS Project como software de gestão e planejamento, além de desenvolver procedimentos de medição e controle com indicadoresmensais. Embora a maior parte dos projetos seja terceirizada, possui um departamento próprio de gestão e coordenação de projetos, que estabelece o escopo de todas as etapas a serem desenvolvidas e controladas em cada empreendimento.

\section{Caracterização do empreendimento 2: implementação da PEO}

O empreendimento 2, escolhido para a segunda proposta de implementação da preparação da execução de obras, é caracterizado como um empreendimento de alto padrão, localizado em um bairro nobre (zona de expansão urbana) da cidade de Goiânia.

Considerado como o primeiro empreendimento da categoria Mixed Use com hotel, salas comerciais e mall na região, foi desenvolvido a partir de duas torres geminadas, com entradas separadas para cada uma das tipologias envolvidas.

O edifício comercial possui 225 salas comerciais, 15 salas corporativas e 4 lojas comerciais no pavimento térreo $(\mathrm{mall})$, enquanto a torre hoteleira conta com 190 apartamentos, e serãoambas as torres construídas em um terreno de 2.594,06 $\mathrm{m}^{2}$.

O empreendimento possui três subsolos, distribuídos da seguinte maneira: 110 vagas comerciais no subsolo 3, 100 vagas comerciais no subsolo 2, 77 vagas comerciais no subsolo 1, e os pavimentos térreo e mezanino foram projetados com 23 e 41 vagas respectivamente para atender os usuários do hotel. Na Figura 5está ilustradoo empreendimento 2, também escolhido com objeto de estudo desta pesquisa.

Figura 5 - Fachada frontal do empreendimento 2

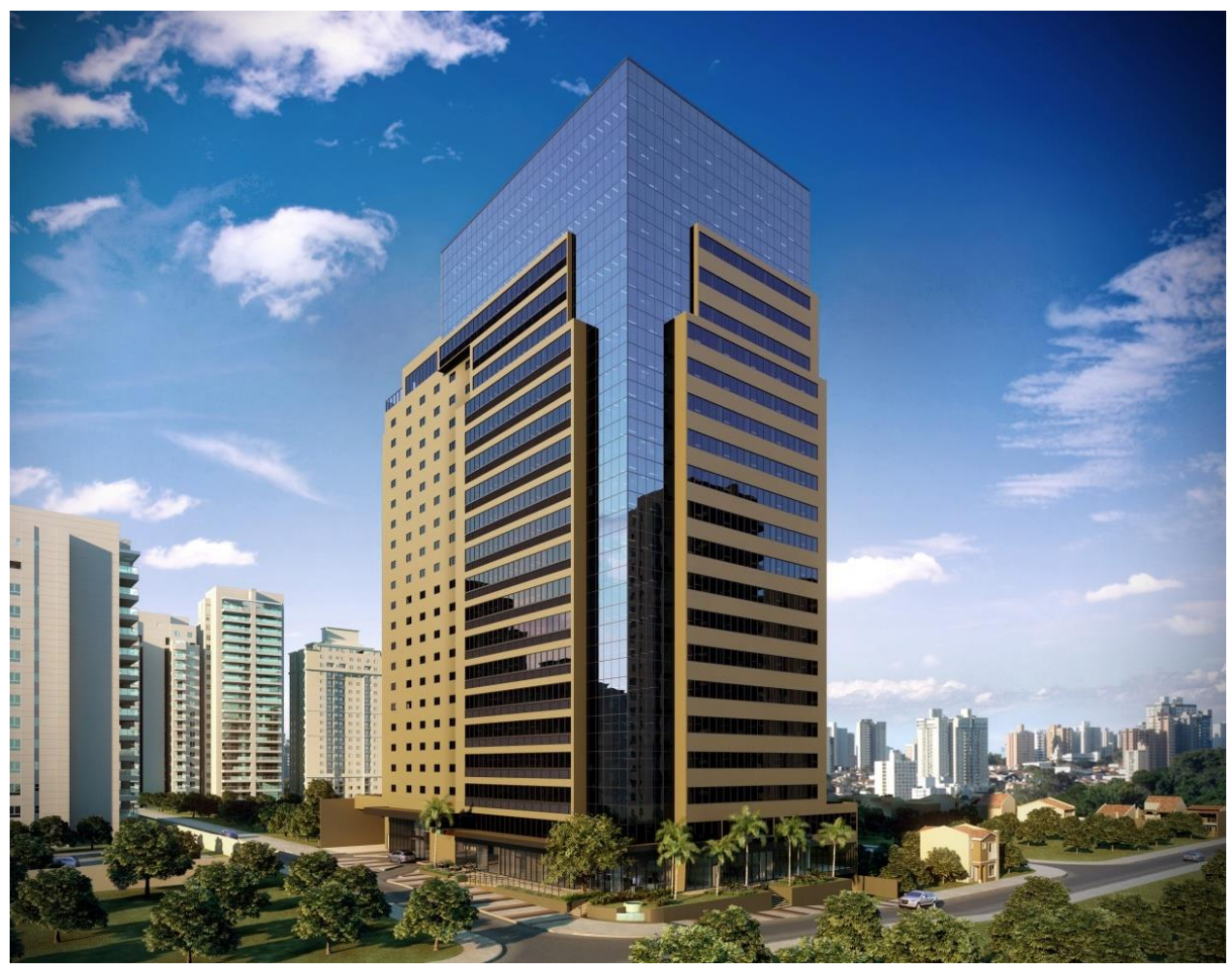

192 Arrotéia, A. V.; Amaral, T. G. do; Melhado, S. B. 


\section{Análise do estudo piloto da PEO na empresa $A$}

Antecipadamente ao início da análise de dados, tanto do estudo piloto na empresa Acomo naimplementação na empresa $\mathrm{B}$, identificou-se $\mathrm{o}$ estágio de evolução em que $\mathrm{o}$ projeto se encontravapara iniciar a fase intensiva de PEO. Dessa forma, foi identificado que o desenvolvimento do projeto do empreendimento 1 estava no nível de projeto executivo detalhado, contudo não havia sido iniciado o projeto de detalhamento antes do início das atividades do estudo piloto na empresa A.

Antes de se iniciar o estudo piloto na empresa A, foram estabelecidos, em conjunto com o coordenador proativo (gerente de planejamento e projetos da empresa), quais seriam os agentes que comporiam a equipe multidisciplinar da fase de preparação da execução de obras. Em um segundo momento, após o estabelecimento da equipe multidisciplinar, foi elaborado um diagnóstico da empresa a partir das observações pessoais do coordenador proativo, juntamente com a coordenadora de PEO.

Para isso, foram realizadas quatro reuniões não formalizadas por meio de atas, anteriormente ao início da fase de PEO no empreendimento 1, com o intuito de discutir aspectos tangentes à estrutura organizacional e departamental da empresa, o formato de contratação dos subcontratados, os tipos e o nível de detalhamento dos projetos realizados, os procedimentos de execução e controle, as medições ou indicadores, entre outros pontos para a elaboração do diagnóstico.

Após a elaboração do diagnóstico da empresa, o estudo piloto na empresa A foi iniciado em 2012, com o lançamento da PEO no empreendimento 1, o qual foi formalizado pela realização da primeira reunião, intitulada "Apresentação do método e reconhecimento dos agentes participantes".

Após o lançamento da PEO, foram realizadas sete reuniões durante a fase de desenvolvimento, o que resultou em oito reuniões efetuadas durante o estudo piloto. De acordo com o método proposto, o estudo piloto cumpriu a realização de oito reuniões durante a fase de preparação da execução de obras.

Todavia, o estudo piloto aplicado na empresa A foi interrompido durante seu desenvolvimento, devido à paralisação da obra e ao desligamento do engenheiro residente responsável pela execução do empreendimento 1. Após a interrupção, foram realizadas mais duas reuniões, destinadas àdiscussão e análise crítica do projeto detalhado de arquitetura do empreendimento.
Com a interrupção da execução da obra e a saída do engenheiro residente, não foi possível dar continuidade às reuniões, uma vez que as decisões foram tomadas durante a fase de PEO em conjunto com este agente. Seria necessário que o estudo piloto retomasse todas as reuniões desenvolvidas a partir da entrada do novo engenheiro residente, o que não foi efetivado. No Quadro 3 está ilustrado o desenvolvimento das reuniões realizadas no empreendimento 1 e em seguida no Quadro 4, os agentes que participaram das reuniões duratne o estudo piloto da PEO na empresa A.

\section{Análise da implementação da PEO na empresa B}

A implementação da PEO na empresa B iniciouseem 2013, a qual objetivou a apresentação do método e do cronograma das reuniões para os agentes participantes. A fase de preparação da execução de obras desenvolveu-se em um período aproximado de 3 meses sem interrupção, visando ao cumprimento das atividades de modo contínuo durante a etapa de preparação do canteiro de obras.

Ao longo desse período foram realizadas nove reuniões, que ocorreram semanal ou quinzenalmente, nas quais a data e o horário foram estabelecidos de acordo com a disponibilidade dos agentes envolvidos, a fim de que todos pudessem participar das reuniões. De forma simplificada, a PEO tem por objetivo "colocar os agentes para conversarem", no intuito de que cada um possa contribuir em sua respectiva área do conhecimento técnico, a fim de promover o envolvimento dos projetistas com a equipe de execução do empreendimento.

Por conseguinte, após a realização das oito reuniões que envolveram as fases de lançamento e desenvolvimento da PEO, a implementação no empreendimento 2 teve seu fim marcado com a nona reunião, realizada no dia 13/08/2013, na qual foram apresentados para a equipe de execução os projetos e os documentos gerados durante o desenvolvimento do método.

Dessa forma, paraum melhor entendimento do desenvolvimento das reuniões na empresa $\mathrm{B}$, foram elaborados dois quadros,que ilustram como as reuniões foram planejadas anteriormente ao início da fase de PEO, e como elas aconteceram no momento da implementação,ou seja, cronogramas das reuniões de $\mathrm{PEO}$ anterior e posterior à implementação, conforme ilustrado no Quadro5. A seguir, no Quadro 6, estão ilustrados os agentes participantes em cada reunião durante a etapa de PEO na empresa B. 
Quadro 3 -Quadro-resumo com as reuniões realizadas durante estudo piloto da PEO

\begin{tabular}{|c|c|c|c|c|}
\hline \multicolumn{5}{|c|}{ AS REUNIÕES DE PEO } \\
\hline \multicolumn{5}{|c|}{ QUADRO RESUMO DAS REUNIÕES REALIZADAS NO ESTUDO PILOTO } \\
\hline FASES & REUNIÃO & DIA/MÊS & TEMA CENTRAL DA REUNIÃO & LOCAL \\
\hline $\begin{array}{c}\text { Lançamento } \\
\text { do estudo piloto }\end{array}$ & $1^{a}$ REUNIÃO & $04 / 05$ & $\begin{array}{l}\text { Apresentação da metodologia e reconhecimento } \\
\text { dos agentes participantes }\end{array}$ & Stand de vendas do empreendimento \\
\hline \multirow{7}{*}{$\begin{array}{l}\text { Desenvolvimento } \\
\text { do estudo piloto } \\
\text { da PEO }\end{array}$} & $2^{\mathrm{a}}$ REUNIÃO & $16 / 05$ & $\begin{array}{l}\text { Reconhecimento do local do empreendimento e } \\
\text { diretrizes para o projeto e o plano de segurança do } \\
\text { canteiro de obras }\end{array}$ & Stand de vendas do empreendimento \\
\hline & $3^{\mathrm{a}}$ REUNIÃO & $23 / 05$ & $\begin{array}{l}\text { Discussão dos projetos do empreendimento e } \\
\text { definição da nova padronização para arquivamento } \\
\text { dos projetos }\end{array}$ & Sede administrativa da empresa \\
\hline & $4^{\mathrm{a}}$ REUNIÃO & $30 / 05$ & $\begin{array}{l}\text { Apresentação e entrega do projeto executivo de } \\
\text { arquitetura do empreendimento }\end{array}$ & $\begin{array}{c}\text { Escritório do projetista de arquitetura } \\
\text { terceirizado }\end{array}$ \\
\hline & $5^{\mathrm{a}} \mathrm{REUNI} \tilde{\mathrm{A} O}$ & $09 / 06$ & $\begin{array}{l}\text { Discussão do projeto e do plano de segurança do } \\
\text { canteiro de obras e síntese dos pontos a controlar }\end{array}$ & Stand de vendas do empreendimento \\
\hline & $6^{\mathrm{a}}$ REUNIÃO & $13 / 06$ & $\begin{array}{l}\text { Finalização do projeto e do plano de segurança } \\
\text { do canteiro de obras }\end{array}$ & Stand de vendas do empreendimento \\
\hline & $7^{\mathrm{a}}$ REUNIÃO & $23 / 06$ & $\begin{array}{l}\text { Tratamento das interfaces técnicas entre os } \\
\text { projetos do empreendimento }\end{array}$ & Stand de vendas do empreendimento \\
\hline & $8^{\mathrm{a}}$ REUNIÃO & $27 / 06$ & $\begin{array}{l}\text { Discussão e análise crítica do projeto executivo } \\
\text { do empreendimento }\end{array}$ & Stand de vendas do empreendimento \\
\hline \multirow{2}{*}{$\begin{array}{l}\text { Após estudo } \\
\text { piloto da PEO }\end{array}$} & $9^{a}$ REUNIÃO & $21 / 08$ & $\begin{array}{l}\text { Apresentação e entrega do projeto } \\
\text { detalhamento do empreendimento }\end{array}$ & $\begin{array}{c}\text { Escritório do projetista de arquitetura } \\
\text { terceirizado }\end{array}$ \\
\hline & $10^{\mathrm{a}}$ REUNIÃO & $25 / 09$ & $\begin{array}{l}\text { Discussão e análise crítica do projeto de } \\
\text { detalhamento do empreendimento }\end{array}$ & $\begin{array}{c}\text { Escritório do projetista de arquitetura } \\
\text { terceirizado }\end{array}$ \\
\hline
\end{tabular}

Quadro 4 - Agentes participantes nas reuniões do estudo piloto da PEO na empresa A

\begin{tabular}{|c|c|c|c|c|}
\hline \multicolumn{5}{|c|}{ AS REUNIÕES DE PEO } \\
\hline \multicolumn{5}{|c|}{ AGENTES PARTICIPANTES NA EMPRESA A } \\
\hline FASES & REUNIÃO & DIA/MÊS & AGENTES PARTICIPANTES EM CADA REUNIÃO & TOTAL \\
\hline $\begin{array}{l}\text { Lançamento } \\
\text { da PEO }\end{array}$ & $1^{\text {a } R E U N I A ̃ O ~}$ & $04 / 05$ & $\begin{array}{l}\text { coordenador pró-ativo, engenheiro residente, técnico de segurança, mestre de obras, } 02 \text { projetistas de } \\
\text { arquitetura, } 02 \text { projetistas de fundação, } 01 \text { projetista de estruturas, } 04 \text { subempreiteiros de duas empresas } \\
\text { diferentes de serviço de obra bruta. }\end{array}$ & 13 \\
\hline \multirow{7}{*}{$\begin{array}{c}\text { Desenvolvimento } \\
\text { da PEO }\end{array}$} & $2^{a}$ REUNIÃO & $16 / 05$ & coordenador pró-ativo, engenheiro residente, 02 técnicas de segurança e o mestre de obras & 05 \\
\hline & $3^{a}$ REUNIÃO & $23 / 05$ & coordenador pró-ativo, engenheiro residente e o estagiário de engenharia & 03 \\
\hline & $4^{a}$ REUNIÃO & $30 / 05$ & coordenador pró-ativo, engenheiro residente e três projetistas de arquitetura & 05 \\
\hline & $5^{\mathrm{a}}$ REUNIÃO & $09 / 06$ & engenheiro residente, mestre de obras e as 02 técnicas de segurança & 04 \\
\hline & $\sigma^{a}$ REUNIÃO & $13 / 06$ & engenheiro residente, 02 técnicas de segurança e o mestre de obras & 04 \\
\hline & 7 REUNIÃO & $23 / 06$ & coordenador pró-ativo, engenheiro residente e coordenadora de PEO & 03 \\
\hline & $8^{a}$ REUNIÃO & $27 / 06$ & mestre de obras, 02 técnicas de segurança, coordenador pró-ativo e o engenheiro residente & 05 \\
\hline \multirow{2}{*}{$\begin{array}{c}\text { Após estudo } \\
\text { piloto da PEO }\end{array}$} & 9 REUNIÃO & $21 / 08$ & coordenador pró-ativo, engenheiro residente e três projetistas de arquitetura & 05 \\
\hline & $10^{\mathrm{a}}$ REUNIÃO & $25 / 09$ & coordenador pró-ativo, engenheiro residente e coordenadora de PEO & 03 \\
\hline
\end{tabular}

Destaca-se que, antes de iniciarem-se as reuniões de PEO na empresa $B$, foi identificado que o desenvolvimento do projeto do empreendimento 2 estava em nível de anteprojeto (projeto legal), e com o projeto executivo em andamento, diferentemente do encontrado no empreendimento 1 da empresa A

\section{Avaliação do método proposto}

Nos dois casos estudados foi constatada a falta de comprometimento dos agentes participantes durante a fase de PEO. Além da falta de participação dos projetistas, identificou-se uma grande rejeição quanto à participação dos

194 Arrotéia, A. V.; Amaral, T. G. do; Melhado, S. B. 
subempreiteiros nas reuniões na visão dos agentes integrantes da empresa,sob a justificativa de que esses profissionais compartilham informações diferentes das dos demais agentes envolvidos e que, por isso, não contribuiriam para o desenvolvimento das ações praticadas na etapa de preparação da execução de obras.

Além disso, foi verificado que o formato de contratação dos serviços técnicos dos subempreiteiros não contribui para a participação desses profissionais na fase de PEO, pois eles são admitidos no momento da execução dos serviços, ou seja, neste período a fase de PEO do empreendimento já foi concluída.
Outro aspecto observado foi a falta de conhecimento sobre o método por parte dos agentes representantes da empresa $\mathrm{B}$, apesar de ele ter sido apresentado na primeira reunião da fase de PEO. Isto é, apesar de os agentes reconhecerem a importância da adoção de reuniões para a discussão do projeto, foi constatado que eles confundem o método da preparação da execução de obras com a etapa de gestão e compatibilização de projetos, anterior à fase de PEO, a qual deveria ser iniciada desde a concepção do projeto do empreendimento.

\section{Quadro 5 - Cronograma planejado x executado da implementação da PEO na empresa B}

\begin{tabular}{|c|c|c|c|c|c|c|c|c|}
\hline \multicolumn{9}{|c|}{ AS REUNIÕES DE PREPARAÇÃO DA EXECUÇÃO DE OBRAS (PEO) } \\
\hline \multicolumn{4}{|c|}{ CRONOGRAMA PLANEJADO } & \multicolumn{5}{|c|}{ CRONOGRAMA EXECUTADO } \\
\hline FASES & REUNLÃo & DIAMÊS & TEMA CENTRAL DA REUNIÃO & FASES & REUNIÃo & DIAMÊS & TEMA CENTRAL DA REUNIÃO & LOCAL. \\
\hline $\begin{array}{l}\text { Lançamento } \\
\text { da PEO }\end{array}$ & $I^{*}$ REUNIÃo & $17 / 05$ & $\begin{array}{l}\text { Apresentação da metodologia e } \\
\text { reconhecimento dos agentes participantes }\end{array}$ & $\begin{array}{l}\text { Lançamento } \\
\text { da PEO }\end{array}$ & $1^{2}$ REUNIÃO & $17 / 05$ & $\begin{array}{l}\text { Apresentação da metodologia e } \\
\text { reconhecimento dos agentes participantes }\end{array}$ & $\begin{array}{l}\text { Sede administrativa } \\
\text { da empresa }\end{array}$ \\
\hline \multirow{6}{*}{ 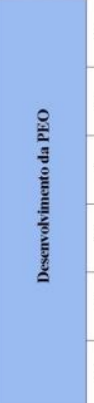 } & $2^{n}$ REUNIÃO & $22 / 05$ & $\begin{array}{l}\text { Reconhecimento do local do empreendimento } \\
\text { e a análise critica dos projetos }\end{array}$ & \multirow{7}{*}{ 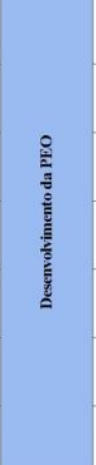 } & $2^{*}$ REUNIÃO & $20 / 05$ & $\begin{array}{l}\text { Discussão e análise crítica dos projetos } \\
\text { envolvidos no empreendimento }\end{array}$ & $\begin{array}{c}\text { Sede administrativa } \\
\text { da empresa }\end{array}$ \\
\hline & $3^{a}$ REUNIÃO & $29 / 05$ & $\begin{array}{l}\text { Discussão do projeto de detalhamento e } \\
\text { tratamento das interfaces técnicas e gerenciais }\end{array}$ & & $3^{*}$ REUNLÃO & $11 / 06$ & $\begin{array}{l}\text { Reconhecimento do local do empreendimento } \\
\text { e continuação da análise crítica dos projetos }\end{array}$ & $\begin{array}{l}\text { Escritório do } \\
\text { canteiro de obras }\end{array}$ \\
\hline & $4^{*}$ REUNIÃo & $07 / 06$ & $\begin{array}{l}\text { Revisão dos contratos relacionados à prestação } \\
\text { dos serviços técnicos dos subempreiteiros }\end{array}$ & & 4" REUNIÃO & $20 / 06$ & $\begin{array}{l}\text { Diretrizes para elaboraç̃a do projeto e do plano } \\
\text { de segurança do canteiro de obras }\end{array}$ & $\begin{array}{l}\text { Escritório do } \\
\text { canteiro de obras }\end{array}$ \\
\hline & $5^{\wedge}$ REUNIÃO & $14 / 06$ & $\begin{array}{l}\text { Diretrizes para elaboração do projeto e do } \\
\text { plano de segurança do canteiro de obras }\end{array}$ & & $5^{*}$ REUNIÃO & $27 / 06$ & $\begin{array}{l}\text { Discussão do projeto e do plano de segurança } \\
\text { do canteiro de obras }\end{array}$ & $\begin{array}{l}\text { Escritório do } \\
\text { canteiro de obras }\end{array}$ \\
\hline & $6^{a}$ REUNIÃO & $21 / 06$ & $\begin{array}{l}\text { Revisão dos procedimentos de execução e } \\
\text { controle }\end{array}$ & & $6^{2}$ REUNLÃO & $05 / 07$ & $\begin{array}{l}\text { Tratamento das interfaces técnicas e revisão } \\
\text { dos procedimentos de medição e controle }\end{array}$ & $\begin{array}{l}\text { Sede administrativa } \\
\text { da empresa }\end{array}$ \\
\hline & $7^{\prime \prime}$ REUNIÃO & $28 / 06$ & $\begin{array}{l}\text { Apresentação dos projetos e sintese dos pontos } \\
\text { à controlar }\end{array}$ & & $7^{*}$ REUNLÃO & $17 / 07$ & $\begin{array}{l}\text { Revisão dos contratos relacionados à prestação } \\
\text { dos serviços técnicos dos subempreiteiros }\end{array}$ & $\begin{array}{l}\text { Escritório do } \\
\text { canteiro de obras }\end{array}$ \\
\hline \multirow[t]{2}{*}{$\begin{array}{l}\text { Finalizaçào } \\
\text { da PEO }\end{array}$} & $8^{*}$ REUNIĀo & $05 / 07$ & Apresentação do dossiê "bom para execução". & & $8^{s}$ REUNIÃO & $30 / 07$ & $\begin{array}{l}\text { Apresentação dos projetos e síntese dos } \\
\text { pontos a controlar }\end{array}$ & $\begin{array}{c}\text { Sede administrativa } \\
\text { da empresa }\end{array}$ \\
\hline & & & & $\begin{array}{c}\text { Finalização } \\
\text { da PEO }\end{array}$ & $9^{\prime}$ REUNIÃO & $13 / 08$ & Apresentação do dossiê "Bom para execução" & $\begin{array}{l}\text { Escritório do } \\
\text { canteiro de obras }\end{array}$ \\
\hline
\end{tabular}

Quadro 6 - Agentes participantes nas reuniões de implementação da PEO na empresa B

\begin{tabular}{|c|c|c|c|c|}
\hline \multicolumn{5}{|c|}{ AS REUNIÕES DE PEO } \\
\hline \multicolumn{5}{|c|}{ AGENTES PARTICIPANTES NA EMPRESA B } \\
\hline FASES & REUNIÃO & DIA/MÊS & AGENTES PARTICIPANTES EM CADA REUNIÃO & TOTAL \\
\hline $\begin{array}{l}\text { Lançamento } \\
\text { da PEO }\end{array}$ & $1^{3}$ REUNIÃO & $17 / 05$ & $\begin{array}{l}\text { projetista de arquitetura do empreendimento, } 2 \text { engenheiras eletricistas, } 2 \text { projetistas de ar condicionado, } \\
\text { gerente técnico da empresa (coordenador pró-ativo), coordenador de projetos e o engenheiro residente. }\end{array}$ & 08 \\
\hline \multirow{5}{*}{$\begin{array}{l}\text { Desenvolvimento } \\
\text { da PEO }\end{array}$} & $2^{\mathrm{a}}$ REUNIÃO & $20 / 05$ & $\begin{array}{l}\text { projetista de arquitetura do empreendimento, } 2 \text { engenheiras eletricistas, gerente técnico da empresa } \\
\text { (coordenador pró-ativo), coordenador e auxiliar de projetos e o engenheiro residente. }\end{array}$ & 07 \\
\hline & $3^{a}$ REUNIÃO & $11 / 06$ & coordenador e auxiliar de projetos, engenheiro residente e o técnico de segurança & 04 \\
\hline & $4^{2}$ REUNIÃO & $20 / 06$ & auxiliar de projetos, engenheiro residente e o técnico de segurança & 03 \\
\hline & $5^{\mathrm{a}}$ REUNIÃO & $27 / 06$ & coordenador e auxiliar de projetos, engenheiro residente, técnico de segurança e coordenador pró-ativo & 05 \\
\hline & $8^{a}$ REUNIÃO & $30 / 07$ & $\begin{array}{l}\text { projetista responsável pelo projeto elétrico, telefônico e SPDA, engenheiro residente, coordenador de } \\
\text { projetos, auxiliar de projetos e o coordenador pró-ativo. }\end{array}$ & 05 \\
\hline $\begin{array}{c}\text { Finalização } \\
\text { da PEO }\end{array}$ & $9^{2}$ REUNIÃO & $13 / 08$ & $\begin{array}{l}\text { coordenador de projetos, auxiliar de projetos, projetista de estruturas, mestre de obras, almoxarife, } \\
\text { engenheiro residente, auxiliar administrativa, estagiário de engenharia e o técnico de segurança }\end{array}$ & 09 \\
\hline
\end{tabular}


Como o estudo piloto da PEO no empreendimento 1 foi interrompido, não foram realizadas entrevistas com os agentes da empresa A. A aplicação do questionário para os três agentes da empresa B resultou nas seguintes observações:

(a) acreditam que o método da PEO é viável de ser implementado;

(b) definemcomo essencial a interação e comunicação entre os agentes na obtenção de melhorias para o projeto;

(c) afirmam a importância de reunir os projetistas com a equipe de obra, pois isso antecipa as decisões adiadas para a fase de execução de obras, apesar de não acontecer na empresa;

(d) não consideram relevante a participação dos subempreiteiros nas reuniões de PEO; primeiro, sob a justificativa da alta rotatividade destes profissionais no mercado; e, em segundo lugar, pelo fato de os subempreiteiros passar a não contribuir para as reuniões, uma vez que buscam apenas facilitar a execução de seus serviços em detrimento da qualidade geral da obra;

(e) consideram que os projetos compatibilizados pelo departamento de projetos da empresa possibilitam a redução das falhas e retrabalhos durante a execução;

(f) consideram que o departamento de projetos ainda precisa se estruturar; $\mathrm{e}$

(g) afirmam que a empresa não realiza reuniões formalizadas com os projetistas e a equipe de execução antes da implementação da PEO.

Apesar das dificuldades encontradas na integração dos agentes envolvidos na produção de um edifício, foi comprovada a importância de se envolverem as equipes de projeto e obra, com exceção dos subempreiteiros, para o desenvolvimento do projeto.

A aplicação do método nas duas empresas estudadas trouxe resultados positivos no que tange à organização do canteiro de obras dos dois empreendimentos, bem como para a discussão e o tratamento das interfaces entre as disciplinas de projeto a partir da análise crítica desenvolvida durante as reuniões. São eles:

(a) planejamento e organização do canteiro de obras por meio da elaboração do projeto de leiaute e do plano de segurança nos empreendimentos das empresas A e B;

(b) análise crítica do projeto executivo e de detalhamento na empresa $\mathrm{A}$, e dos projetos em andamento ao nível executivo na empresa B; (c) análise dos pontos críticos dos projetos que resultam em interferências na execução dos empreendimentos das empresas A e B;

(d) tratamento das interfaces entre disciplinas de projeto nos dois casos estudados;

(e) envolvimento das equipes de projeto e obra com as reuniões de PEO nas empresas A e B;

(f) criação do acesso na intranet da empresa B para que os projetistas possam hospedar as versões atualizadas dos projetos;

(g) apresentação do projeto do empreendimento para a equipe de execução da empresa B;

(h) identificação da necessidade de estabelecer reuniões sistematizadas para o estudo do projeto na empresa B;

(i) previsão nos futuros contratos da participação dos projetistas nas reuniões de compatibilização de projetos na empresa B;

(j) revisão dos procedimentos de execução e controle e dos contratos de prestação de serviços técnicos dos subempreiteiros na empresa B;

(k) definição da participação obrigatória dos projetistas nas reuniões de compatibilização de projetos nos próximos empreendimentos da empresa B;

(1) consciência de que é preciso mudar o pensamento com relação à gestão e à coordenação do processo de projeto.

Pode-se afirmar que o método da PEO é aplicável na produção de edifícios, desde que seja planejada com antecedência;ou seja, a partir do momento em que a empresa decide incorporá-la e acredita nas melhorias que ela pode trazer para a interface projeto-execução de obras, faz-se necessário que ela adote algumas iniciativas para que a implementação da PEO seja mais eficaz.

O primeiro passo deve ser tomado pela diretoria da empresa, de modo que a escolha do método objetivea melhoria do projeto e permita a redução de falhas, erros e retrabalhos comumente encontrados na produção de edifícios. Para tanto, faz-se necessário que a participação de seus colaboradores esteja vinculada às metas da empresa com incentivo financeiro.

A segunda iniciativa envolve a mudança no modo de contratação dos projetistas e dos subempreiteiros. Para que a PEO traga melhores resultados para a empresa, é fundamental que todos os agentes envolvidos na construção do empreendimento participem das reuniões de modo ativo. Sendo assim, é preciso que os contratos incorporem a participação obrigatória desses profissionais, a fim de que esses agentes possam 
envolver-se desde a concepção inicial do empreendimento.Em outras palavras, para que os resultados sejam satisfatórios, é fundamental que haja uma mudança na postura das empresas diantedo método.

A terceira iniciativa para a implementação da PEO, não abrangida por esta pesquisa, está relacionada à participação do coordenador proativo na organização e no desenvolvimento das reuniões, bem como à continuidade das ações praticadas na fase de PEO por meio da coordenação proativa. Portanto, é fundamental que este agente trabalhe em conjunto com o coordenador de PEO e com o coordenador de projetos da empresa.

$\mathrm{E}$, por fim, a quarta iniciativa, que complementa as anteriores, é que a gestão seja iniciada nas fases iniciais do projeto. Isto é, a gestão do processo de projeto deve ser desenvolvida de modo contínuo, desde o início do projeto, eao mesmo tempo, formalizada por meio de reuniões sistematizadas que priorizem a comunicação e a interação das equipes de projeto e obra.

\section{Conclusões}

Foi possível avaliar a gestão da interface projetoexecução de obras por meio da aplicação do método da PEO nas empresas estudadas, apesar das limitações encontradas durante sua aplicação devido às dificuldades em reunir os agentes de projeto e execução de obras durante a pesquisa.Desse modo, a análise de dados apontou a falta de participação de projetistas e do coordenador proativo da empresa B em algumas reuniões, além dos subempreiteiros quenão participaram de nenhuma reunião durante a fase de PEO.

Esse cenário reflete a dificuldade na comunicação entre os agentes da construção civil por meio de uma sistemática de reuniõesque promovam a comunicação "face a face" desses agentes, visando à integração das etapas de projeto e obra, ainda considerada fragmentada no setor da construção civil brasileira.

Logo, entende-se que o contexto desejável para a realização da preparação da execução de obras é ter agentes motivados no compartilhamento de ideias, de modo que cada um possa contribuir em sua área técnica do conhecimento, assim como é fundamental que os agentes participantes da empresa, em especial, o coordenador proativo e o coordenador de projetos, tenham conhecimento mais profundo sobre o método da PEO antes de sua implementação, para que possam se envolver de forma mais ativa no desenvolvimento da fase de preparação da execução de obras.
Diante do exposto, faz-se necessária uma mudança de cultura na valorização do projeto, dada sua importância no desempenho e na qualidade ao longo do ciclo de vida do edifício. Portanto, esta pesquisa afirma a importância da continuidade desse tema de pesquisa no meio acadêmico, inicialmente proposto por Souza (2001), porque, além da PEO, existe a discussão de outros métodos em outros países que promovem a integração das equipes de projeto e obra.

Ademais, a PEO não deve ser entendida como um método de gestão rígido, verificando-se a possibilidade de alteração no sequenciamento das reuniões anteriormente proposto, o que demonstra flexibilidade quanto à temática a ser discutida em cada reunião.

Sendo assim, entende-seque o método da PEO deve apresentar diferentes formas de aplicação,de acordo com os aspectos organizacionais das empresas de construção civil, ou seja, propõe-se que a PEO contemple níveis de maturidade diferentes, para que sua implementação seja mais coerente com as particularidades de cada empresa.

Para além disso, o resultado final da PEO pode ser maximizado a partir da adoção dos princípios da engenharia simultânea como sistemática de projeto e da inserção de novas tecnologias computacionais que trabalhem o modelo tridimensional do edifício.

Do mesmo modo,a inserção de novos softwarescomputacionais que operema tecnologia BIM potencializa a aplicação do método da $\mathrm{PEO}$ na construção de edifícios, pois, uma vez tendo sido o projeto desenvolvido a partir de um modelo em três dimensões, deve ser alimentado constantemente, em virtude das alterações que a construção do edifício gera no projeto ao longo da fase de execução.

Dessa forma, a atualização do modelo projetual do edifício somente pode ser realizada a partir de um sistema de reuniões ou encontros formalizados que promovam a comunicação e a interação dos agentes "face a face", o que coincide com a proposta da PEO.

Por fim, mediante as pesquisas nacionais e internacionais publicadas recentemente, as quais afirmam a relevância de continuar estudando esse tema no meio acadêmico, e de acordo com as dificuldades encontradas durante a realização da pesquisa, propõem-se como sugestões para trabalhos futuros:

(a) a implementação do método da coordenação proativa (CPA)e do processo de avaliação participativa e retroalimentação (APR) em empresas de construção e incorporação de 
edifícios, visando à continuidade das ações desenvolvidas durante a fase de PEO;

(b) a implementação do método da PEO em empreendimentos construídos pelo setor público;

(c) o estudo de ferramentas de gestão que contribuam para a interação e a comunicação dos agentes envolvidos na construção de um empreendimento;

(d) a análise por meio de indicadores que quantifiquem a conformidade técnica, ou seja, a diminuição dos erros e retrabalhos na fase de execução do empreendimento após a implementação da PEO;

(e) a proposição de um organograma ideal para a realização da PEO de modo mais eficaz, o qual descreva o perfil e as mudanças necessárias para cada agente participante;

(f) o estudo do modelo do edifício em três dimensões gerado a partir da ferramenta computacional BIM,o qual pode apoiar a aplicação do método da PEO para a integração dos agentes em torno desse protótipo tridimensional.

\section{Referências}

ANDI, M. T. Design Documents Quality in the Japanese Construction Industry: factors influencing and impacts on construction process. International Journal of Project Management, v. 21, p. 537-546, 2003.

\section{ASSOCIATION FRANÇAISE DE}

NORMALIZATION. NF P 03-001 : cahier des clauses administratives générales applicable aux travaux de bâtiment faisant l'object de machés privés. France, 2000.

AUSTIN, S.et al. Analytical Design Planning Technique: a model of the detailed building design processes. Design Studies, v.20, n.3, p.279-296, May 1999.

AZAM, M. A. M. et al.An Information Strategy to Support Effective Construction Design Decision Making. In: ANNUAL ARCOM CONFERENCE, 14., 1998, University of Reading Association of Researchers in Construction management, v.1, p.248-257, 1998.

BEIM, A.; JENSEN, K. V. Forming Core Elements For Strategic Design Management: how to define and direct architectural value in industrialized context. United Kingdom, v. 3, n. 1, p. 29-38, 2007.
CONSTRUCTION INDUSTRY INSTITUTE.

[Home page]. Disponívelem:

$<$ https://www.construction-

institute.org/scriptcontent/index.cfm>. Acesso em: 20 mar. 2012.

\section{ECOLE CHEZ SOI. Préparation Avant les}

Travaux. 2004. Disponível em:

<http://www.ecolechezsoi.com>. Acessoem: 1 set. 2013.

EDWIN, H. W. et al. Contract Strategy For Design Management in the Design and Build System. International Journal of Project Management, v. 2, p. 630-639, 2005.

\section{EMMITT, S. Managing Interdisciplinary}

Projects: a primer for architecture, engineering and construction. London: Taylor and Francis, 2010.

EMMITT, S.; PRINS, M.; OTTER, A. D. Architectural Management. Oxford: WileyBlackwell, 2009.

EMMITT, S.; GORSE, C. Communication in Construction Teams. London: Taylor and Francis, 2007.

HILL, C.J. Communication on Construction Sites. In: ASSOCIATION OF RESEARCHERS IN CONSTRUCTION MANAGEMENT ANNUAL CONFERENCE, 11., New York, 1995. Proceedings... New York, 1995.

KOVACIC, I.; OBERWINTER, L.; MÜLER, C. BIM-Supported Planning Process For Sustainable Buildings: Process Simulation and Evaluation through Exploratory Research. In: WORLD BUILDING CONGRESS, Queensland, 2013. Proceedings... Queensland, 2013.

MANSO, M. A.; MITIDIERI FILHO, C. V. Gestão e Coordenação de Projetos em Empresas Construtoras e Incorporadoras: da escolha do terreno à avaliação pós-ocupação. São Paulo: Pini, 2011.

MANZIONE, L. Proposição de Uma Estrutura Conceitual de Gestão do Processo de Projeto Colaborativo Com o Uso do BIM. São Paulo, 2013. $371 \mathrm{f}$. Tese (Doutorado em Engenharia Civil) - Escola Politécnica, Universidade de São Paulo, São Paulo, 2013. 
MARTINS, R. M. de P.; ANDERY, P. R. P.; STARLING, C. M. D. Um Estudo Prospectivo do Processo de Projeto em Obras de Readequação Predial em Instituição Universitária Pública. In: SIMPÓSIO BRASILEIRO DE QUALIDADE DO PROJETO NO AMBIENTE CONSTRUÍDO, 3.; ENCONTRO BRASILEIRO DE TECNOLOGIA DE INFORMAÇÃO E COMUNICAÇÃO NA CONSTRUÇÃO, 6., Campinas, 2013. Anais... Porto Alegre: ANTAC, 2013.

MELHADO, S. B. et al. Uma Perspectiva Comparativa da Gestão de Projetos de Edificações no Brasil e na França. Revista Gestão \& Tecnologia de Projetos, São Paulo, v.1, n.1, p.122, 2006.

MELHADO, S. B. Gestão, Cooperação e Integração Para Um Novo Modelo Voltado à Qualidade do Processo de Projeto na Construção de Edifícios. São Paulo, 2001. 235 f. Tese (LivreDocência) - Escola Politécnica, Universidade de São Paulo, São Paulo, 2001.

MITCHELL, A.et al. A Conceptual Framework of the Interface Between the Design and Construction Processes.Engineering Construction and

Architectural Management, v.18, n.3, p.297-311, 2011.

NATIONAL INSTITUTE OD STANDARDS AND TECHNOLOGY.[Home page]. Disponível em: <http://www.nist.gov/index.html>. Acesso em: 20 mar. 2012.

PRIETO, J.; PÁEZ, H.; VARGAS, H. Sistemas de Información Para la Gerencia de Proyectos: estandarización de procesos y herramientas computacionales. In: ENCUENTRO LATINO AMERICANO DE GESTIÓN Y ECONOMÍA DE LA CONSTRUCCIÓN, 7., Santiago, 2011.

Anais... Santiago: ANTAC, 2011.

PIERCE JUNIOR, D. R. Project Scheduling and Management for Construction.3. ed. Kingston: Construction Publishers \& Consultants, 2004.

RÉGIE DES BATIMENTS.Manuel de Référence Pour UneGestion Qualitative de Chantier de la Régie des Bâtiments.Bruxelas, 2011.Disponível em:

<www.buildingsagency.be/120109_integr_FR.pdf >. Acesso em: $1^{\circ}$ set.2013.

ROMANO, F. V. Modelo de Referência Para o Gerenciamento do `Processo de Projeto Integrado de Edificações. Florianópolis, 2003. $381 \mathrm{f}$. Tese (Doutorado em Engenharia Civil) Escola de Engenharia, Universidade Federal de Santa Catarina, Florianópolis, 2003.
SANCHEZ, A.C.C.; ANDERY, P. R. P. Problemas de Coordenação de Projetos e Sua Relação Com Ações em Obra. In: SIMPÓSIO BRASILEIRO DE QUALIDADE DO PROJETO NO AMBIENTE CONSTRUÍDO, 3.; ENCONTRO BRASILEIRO DE TECNOLOGIA DE INFORMAÇÃO E COMUNICAÇÃO NA CONSTRUÇÃO, 6., Campinas, 2013. Anais... Porto Alegre: ANTAC, 2013.

SAID, H.; EL-RAYES, K. Optimizing the Planning of Construction Site Security For Critical Infrastructure Projects: automation in construction. Urbana, v. 9, p. 221-234, 2010.

SOUZA, L. L. A.; AMORIM, S. R. L.; LYRIO, A. M. Impactos do Uso do BIM em Escritórios de Arquitetura: oportunidade no mercado imobiliário. Revista Gestão \& Tecnologia de Projetos, São Paulo, v.4, n.2, p.26-53, 2009.

SOUZA, A. L. R.; MELHADO, S. B. Preparação da Execução de Obras. São Paulo: O Nome da Rosa, 2003.

SOUZA, A. L. R. Preparação e Coordenação da Execução de Obras: transposição da experiência francesa para a construção brasileira de edifícios. São Paulo, 2001. 463 f. Tese (Doutorado em Engenharia Civil) - Escola Politécnica, Universidade de São Paulo, São Paulo, 2001.

SOUZA,A. L. R. et al. Recomendações Práticas Para a Implementação da Preparação e Coordenação da Execução de Obras. São Paulo, EPUSP, 2001. (BT/PCC/304).

THOMAS, S.R. et al.Critical Communication Variables. Journal of Construction Engineering and Management, v.124, n.4, p.58-66, jan./fev. 1998.

TOSTA, J. P.; CALMON, J. L. Restrições de Projeto Associadas às Etapas de Execução de Edifícios. In: SIMPÓSIO BRASILEIRO DE QUALIDADE DO PROJETO NO AMBIENTE CONSTRUIIDO, 3.; ENCONTRO BRASILEIRO DE TECNOLOGIA DE INFORMAÇÃO E COMUNICAÇÃO NA CONSTRUÇÃO, 6 ., Campinas, 2013. Anais... Campinas: ANTAC, 2013.

VENTURA, A.; PRATSCHKE, A. Experiência de Gestão de Um Processo de Projeto Paramétrico, Com Superfícies Complexas. In: SIMPÓSIO BRASILEIRO DE QUALIDADE DO PROJETO NO AMBIENTE CONSTRUIIDO; ENCONTRO BRASILEIRO DE TECNOLOGIA DE INFORMAÇÃO E COMUNICAÇÃO NA CONSTRUÇÃO, Campinas, 2013. Anais... Campinas: ANTAC, 2013. 
YANG, J. B.; WEI, P. R. Causes of Delay in the Planning and Design Phases For Construction Projects. Journal of Architectural Engineering, Reston, v.16, n.2, p. 80-83, 2010.
XUE, X.; SHEN, K.; REN, Z. Critical Review of Collaborative Working in Construction Projects: Business Environment and Human Behaviors. Journal of Management in Engineering, Reston, v.26, n.4, p.196-208, 2010.

\section{Apêndice}

\begin{tabular}{|c|}
\hline QUESTIONÁRIO PARA AVALIAÇÃO DA PEO JUNTO AOS AGENTES \\
\hline $\begin{array}{l}\text { EMPRESA: } \\
\text { ETAPA/EMPREENDIMENTO: } \\
\text { AGENTE ENTREVISTADO: } \\
\text { LOCAL E DATA: }\end{array}$ \\
\hline 1. Você conhecia o método da preparação da execução de obras? \\
\hline 2. Qual é a sua opinião a cerca do método? Você o considera viável? \\
\hline 3. Quais são suas críticas nas ações desenvolvidas do método? \\
\hline $\begin{array}{l}\text { 4. Em sua opinião a implementação da PEO trouxe ganhos para a empresa? Se sim, } \\
\text { quais? }\end{array}$ \\
\hline $\begin{array}{l}\text { 5. Em sua opinião a implementação da PEO trouxe resultados positivos para o projeto } \\
\text { do empreendimento? Se sim, quais? }\end{array}$ \\
\hline $\begin{array}{l}\text { 6. Antes da implementação da PEO, a empresa realizava algum tipo de encontro } \\
\text { formalizado com os projetistas e a equipe de obra para a discussão do projeto e a } \\
\text { preparação do canteiro? }\end{array}$ \\
\hline $\begin{array}{l}\text { 7. Qual a sua opinião sobre a interação dos agentes de projeto e execução formando } \\
\text { uma equipe de construção? }\end{array}$ \\
\hline $\begin{array}{l}\text { 8. Em sua opinião é possivel reunir todos os agentes, sendo eles os projetistas, } \\
\text { subempreiteiros, consultores e equipe de obra? Se não, quais são as dificuldades } \\
\text { encontradas? }\end{array}$ \\
\hline $\begin{array}{l}\text { 9. Como você qualifica a prestação de serviço dos seus parceiros, como projetistas e } \\
\text { subempreiteiros? }\end{array}$ \\
\hline $\begin{array}{l}\text { 10. Qual é a sua opinião sobre a gestão e coordenação de projetos na empresa? Qual } \\
\text { seria a sua nota de } 0 \text { a } 10 \text { ? }\end{array}$ \\
\hline $\begin{array}{l}\text { 11. Você considera que os projetos compatibilizados pelo departamento de projetos da } \\
\text { empresa possibilitam a redução das falhas e retrabalhos durante o processo produtivo? } \\
\text { Se sim, cite exemplos. }\end{array}$ \\
\hline 12. Você acredita que a empresa irá adotar a PEO nos próximos empreendimentos? \\
\hline
\end{tabular}

\section{Aline Valverde Arrotéia}

Escola de Engenharia Civil | Universidade Federal de Goiás | Praça Universitária, s/n, Setor Universitário | Goiânia - GO - Brasil | CEP 74605-220 | Tel.: (62) 3209-6084 | E-mail: a_arroteia@hotmail.com

Tatiana Gondim do Amaral

Escola de Engenharia Civil | Universidade Federal de Goiás | E-mail: tatiana_amaral@hotmail.com

\section{Silvio Burranttino Melhado}

Escola Politécnica | Universidade de São Paulo | Av. Prof. Almeida Prado, Travessa 2, Cidade Universitária | Sao Paulo - SP - Brasil | CEP 05538-020 | Tel.: (011) 30915164 | E-mail: silvio.melhado@usp.br

\section{Revista Ambiente Construído}

Associação Nacional de Tecnologia do Ambiente Construído

Av. Osvaldo Aranha, $99-3^{\circ}$ andar, Centro

Porto Alegre - RS - Brasil

$$
\text { CEP } 90035-190
$$

Telefone: +55 (51) 3308-4084

Fax: +55 (51) 3308-4054

www.seer.ufrgs.br/ambienteconstruido

E-mail: ambienteconstruido@ufrgs.br 